\title{
Study of HSPB6: Insights into the Properties of the Multifunctional Protective Agent
}

\author{
Fazhao $\mathrm{Li}^{\mathrm{a}} \mathrm{Han}_{\mathrm{Xiao}}^{\mathrm{b}}$ Fangfang Zhou ${ }^{\mathrm{b}}$ Zhiping $\mathrm{Hu}^{\mathrm{b}}$ Binbin Yang ${ }^{\mathrm{b}}$ \\ aDepartment of General Surgery, 2nd Xiangya Hospital, Central South University, ${ }^{b}$ Department of \\ Neurology, 2nd Xiangya Hospital, Central South University, Changsha, Hunan Province, China
}

\section{Key Words}

HSPB6 • Phosphorylation • Chaperon activity • Smooth muscle relaxation • Cardioprotection - Neuroprotection

\begin{abstract}
HSPB6(Heat shock protein B6), is also referred to as P20/HSP20. Unlike other many other members of sHSP(small Heat shock protein) family, which tend to form high-molecular-mass oligomers, in solution, human HSPB6 only forms dimers. However, it still exhibits chaperon-like activity comparable with that of HSPB5. It is expressed ubiquitously, with high and constitutive expression in muscular tissues. sHSPs characteristically function as molecular chaperones and HSPB6 also has a molecular chaperone activity. HSPB6 is up-regulated in response to diverse cellular stress or damage and protect cells from otherwise lethal conditions. HSPB6 is widely recognized as a principle mediator of cardioprotective signaling and recent studies have unraveled the protective role of HSPB6 in disease or injury to the central nervous system. Moreover, accumulating evidence has implicated HSPB6 as a key mediator of diverse vital physiological processes, such as smooth muscle relaxation, platelet aggregation. The versatility of HSPB6 can be explained by its direct involvement in regulating different client proteins and its ability to form heterooligomer with other SHSPs, which seems to be dependent on HSPB6 phosphorylation. This review focuses on the properties including expression and regulation pattern, phosphorylation, chaperon activity, multiple cellular targets of HSPB6, as well as its possible role in physical and pathological conditions.

\section{Introduction}

Acting as ATP-independent molecular chaperones, all sHSPs play important roles in protein house-keeping. sHSPs have low subunit molecular masses of 12-43 kDa and are characterized by the presence of a highly conserved region of 80-100 amino acids in their C-terminal domains called the " $\alpha$-crystallin domain" (ACD) that is flanked by NTD and CTE. Human genome contains 10 genes coding different members of the family of small heat shock proteins (HSPB1-10). As a member of sHSP family, HSPB6 was originally identified as a 
byproduct of purification of human HSPB1[1]. HSPB6 is constitutively expressed in a variety of tissues, while at high levels in skeletal, cardiac and smooth muscle [2]. Beyond the ACD highly conserved across all metazoan sHSPs, the most distinct feature of HSPB6 is its short C-terminal extension void of the anchoring I-I/V motif [3, 4]. A majority of sHSPs form large oligomers, a property that has been linked to their effective chaperone action. Importantly, while in solution human HSPB6 only forms dimers [5], it still has equivalent chaperon activity to HSPB5[6]. This finding provides new information relative to the model that suboligomeric sHSP forms are a substrate binding species. HSPB6 expression levels and phosphorylation at Ser16 can be induced by a wide range of stimuli $[7,8]$. Phosphorylation, as a prominent posttranslational modification of HSPB6, significantly affects HSPB6 conformational structure and modulates the interaction of HSPB6 with the target proteins, its chaperonelike activity, thus influencing many physiologically important events, including smooth muscle relaxation [9], regulation of platelet function and its protective role in heart [10]. Moreover, HSPB6 expression inversely correlated with the grade of malignancy suggesting its potential to be a diagnostic, predictive or prognostic biomarker in cancers $[11,12]$. Recent researches have also defined roles of HSPB6 in brain $[13,14]$. Our previous work discovered that neuronal HSPB6 overexpression rendered protection against ischemia in vitro [15]. This review highlights the structure characteristic, expression, posttranslational modifications of HSPB6; the putative mechanisms of its actions in physiological and pathological conditions and the therapeutic implications.

\section{HSPB6 as a dimer in solution}

Though the recombinant rat HSPB6 formed an equilibrium mixture of two differently sized oligomers [16], the true solution form of the full-length human HSPB6 is a dimer, independent of protein concentration or HSPB6 phosphorylation [5]. The C-terminal domain of many sHSPs contains a conserved tripeptide sequence I/L-X-I/L, which patches hydrophobic groove between strands $\beta 4$ and $\beta 8$ of the ACD and is involved in the interdimer interactions. The most distinct feature of HSPB6 is its short CTE void of this anchoring module [5]. In the archetypal metazoan, mutation of hydrophobic I/V residues in alphacrystallins does not abolish the formation of large oligomers, suggesting, at least for the vertebrate sHSPs, that there are additional interactions for this phenomenon. It is widely accepted that NTE of some sHSPs includes various contact sites for intersubunit interaction and contributes to oligomeric organization [17]. Consistently, three-dimensional structure reveals positive contribution of the tripeptide motifs, found in the NTD, to self-association of HSPB6 via inter-dimer patching of the $\beta 4 / \beta 8$ grooves [5]. Importantly, in the presence of TMAO, which to some extent mimics crowded intracellular environment, HSPB6 is present as an equilibrium mixture of different size oligomers [18]. Importantly, HSPB6 phosphorylation cause drastic reduction of TMAO induced oligomerization. As phosphorylation reportedly weakens NTD interactions, resulting in destabilization of interdimer interaction and oligomerization $[19,20]$, it is proposed that addition of TMAO may alter structural flexibility of NTD and that its effect, therefore, can be counteracted by HSPB6 phosphorylation [18]. Taking into account high cellular concentration of HSPB6 and molecular crowding within cell, human HSPB6 could readily undergo oligomeric state in vivo. HSPB6 has been demonstrated to assemble into hetero-oligomers with sHSPs and in some cases with other proteins in the mammalian cytosol, the apparent dimeric structure of this sHSP is thus indeed limited to the recombinant form.

\section{Expression and regulation of HSPB6 in animal models}

HSPB6 is ubiquitously expressed [1], reaching a maximal level of $1.3 \%$ of total proteins in skeletal and smooth muscle. Expression of HSPB6 can be dramatically changed during 
variety of chemical and physiological stresses. HSPB6 expression has been reported to increase over the course of ontogenesis in rat hindlimb muscles [21] as well as in pig heart and skeletal muscle [22]. HSPB6 is highly expressed during early and mid-pregnancy and then the expression markedly decreases as the uterus progresses toward labor [23]. Coupled with documented evidence that HSPB6 regulates smooth muscle contraction, the observation implicates a role for HSPB6 in the regulation of myometrial quiescence during early and mid-pregnancy and in relieving contractile inhibition of the myometrium late in gestation. Although expression of HSPB6 did not seem to be heat-inducible in rat tissue [1], heat pretreatment of swine carotid artery was associated with increased HSPB6 and ser16-HSPB6 phosphorylation level [24]. Transiently increased HSPB6 levels in rat heart were observed upon LPS stimulation [25], after exercise training [26] and under doxorubicin treatment [27]. HSPB6 levels and phosphorylation were strongly upregulated upon $\beta$-agonist stimulation [8], as well as in tachycardia-induced canine failing heart [28]. These studies indicate that both transcriptional activation and posttranslational modification might provide fine tuning of HSPB6 activity in the cell.

HSPB6 is the only sHSP responsive to both acute and chronic hyperglycemia in mouse hearts. Expression of HSPB6 increased under acute hyperglycemia, whereas decreased upon chronic hyperglycemia [29]. Further study indicated that chronic diabetic cardiomyocytes contain higher levels of miR-320 than healthy ones, leading to reduced protein levels of HSPB6 [30]. This means that the level of HSPB6 in the cell is regulated via different mechanism in different tissues and under different conditions.

HSPB6 is also detected, although in relatively a small amount in the nervous system. HSPB6 expression increased during brain development, indicating it is more important in adulthood. After SAH, HSPB1 phosphorylation increased while HSPB6 and its phosphorylation level decreased in cerebral vessels [31]. As HSPB6 is dynamically associated with vasodilatation [32], the hypothesis is that vasospasm induced by SAH might be attributable to impaired relaxation which might be associated with changes of the sHSP. In the cultured hippocampal neurons, though not up-regulated by heat shock, the mRNA and protein level of HSPB6 were upregulated upon sublethal sodium arsenite, oxidative and hyperosmotic stress [33]. The survival of mammalian cells exposed to adverse environmental conditions requires a radical reprogramming of protein translation, which is characterized by globally downregulated protein synthesis followed by a selective translation of stress related transcripts [34]. The translation reprogramming is proposed to account for the earlier increase at mRNA level than at the protein level in this study. HSPB6 was found upregulated as an early response to hypoxia of the newborn in the hippocampus but not in the cortex or cerebellum [35]. It is possible that the hippocampus, a functionally crucial area of the brain that is particularly sensitive to hypoxic stress, benefits from the vascular relaxation induced by the increased expression of HSPB6 and thus develops tolerance against ischemic stress [35]. HSPB6 expression within the restricted location in the hippocampal CA1 increased both in an acute and a subacute phase after ischemia, while phosphorylated HSPB6 was just observed during subacute phase, suggesting a two-phase role of HSPB6 in brain ischemia: an acute phase before DNA fragmentation and a subacute phase 2 weeks after ischemia [36]. In MS, HSPB6 were increased significantly in WM, especially the center of chronic active lesions; no such induction was observed in GM lesions. which exclusively found in astrocytes but not in oligodendrocytes, microglia or neurons, but not in GM lesions [37]. The differential expression between WM and GM suggested that GM areas in an MS-affected CNS may benefit much less from the protective functions of HSPB6 than WM areas [37].

\section{Intracellular and extracellular location of HSPB6}

Intracellular location of HSPB6 has been analyzed in a number of investigations; however, the results still remain a subject of debate. In swine carotid arteries, HSPB6 is located throughout the cytoplasm [38]. In adult rat hearts, HSPB6 is a predominantly 
cytosolic protein, however, a small subset of HSPB6 is associated with HSPB5 and localizes to distinct transverse bands and sarcomeric actin [32]. In vascular smooth muscles, subcellular distribution of HSPB6 do not change with stimulation [39]. On the contrary, intracellular localization of HSPB 6 changes in cardiomyocytes in response to stress. In cultured rat neonatal cardiomyocytes, heat stress results in partial redistribution of HSPB6 from the cytoplasm to the nucleus. Under ischemic conditions, HSPB6 is prominently translocated from cytosol to the Z/I-area of ischemic myofibrils [40]. HSPB6 in rat cardiac myoblasts is translocated to actin cytoskeleton upon proteasomal inhibition [41] as well as isoproterenol stimulation [42]. Collectively, these data demonstrate that, in response to cellular stress, HSPB6 tends to translocate to myofibrils or elements of the cytoskeleton where it probably binds to partially denatured proteins, and by this means, it can participate in protection of contractile apparatus.

Notably, HSPB6 is detectable in blood and is believed to inhibit platelet aggregation [43]. Moreover, Kozawa et al. found markedly reduced HSPB6 level in arterial wall with elevated HSPB6 concentrations in plasma of cardiomyopathic hamsters after endothelial injury. Since HSPB6 is a typical intracellular protein, the observations indicated that at least part of HSPB6 remains free in cytosol and is liberated upon injury [44]. Subsequent researches showed that HSPB6 was secreted from adult rat cardiomyocytes via exosomes, independent of the classical ER-Golgi protein export pathway, under both steady state and stressed conditions. Circulating HSPB6 functions as a mediator of angiogenesis [45], which enhances the survival of cardiomyocytes.

\section{Chaperon activity of HSPB6}

Rat HSPB6 was originally described to be a poor chaperone [16], but more recent studies have shown that the human orthologue exhibits chaperone-like activity [6]. At a neutral or slightly alkaline pH, HSPB6 has comparable or even higher chaperone activity than HSPB5[6]. While acidification decreased the chaperone activity of HSPB5 slightly, it led to significant decrease in the chaperone activity of HSPB6. A number of studies suggest that HSPB6 acts as a molecular chaperone by preventing denatured alcohol dehydrogenase and $\mathrm{A} \beta$ aggregation [46].

It is now accepted that oligomeric architectures are important for sHSPs to form chaperone:client complexes under stress. The oligomeric dissociation that mediates subunit exchange is strongly correlated with sHSP chaperone activity and its regulation. However, the chaperone activity of the dimeric HSPB6 clearly demonstrates that dissociation of the oligomers was not a prerequisite for the sHSP's activity of substrate binding and formation of sHSP-substrate complex. This finding also adds support to the model in which dimers that are released from oligomeric sHSPs, either by subunit exchange or temperature-induced dissociation, are the active chaperoning unit.

NTD, which is located on the inner surface of the oligomer, may undergo conformational change upon various stimuli and exposes hydrophobic binding sites for denaturing substrate, acting as a tentacle to bind the client protein [47]. The importance of the NTD in substrate interactions is consistent with activity measurements of HSPB6 truncation mutants. Partial deletions in the NTD have been demonstrated to radically affect chaperon activity of HSPB6, and complete removal of the NTD showed full loss of activity, pointing to the presence of multiple, redundant substrate binding sites for binding unfolding proteins [4]. The emergent picture is that binding is probably different for different substrates dependent on the conformation of surfaces exposed when substrates unfold. While the majority of truncations had a negative effect on chaperone-like activity, unexpectedly, deletion of a highly conserved region (residues 31 to 35 ) greatly enhanced chaperoning capability [4].

As previous reviewed, patching of the hydrophobic $\beta 4 / \beta 8$ groove by NTD or C-terminal I-I/V motif facilitates oligomer formation. In addition to its established role in sHSPs oligomerization, the hydrophobic groove in HSPB6 links the sHSPs to the degradation of

\section{KARGER}


Fig. 1. Summary of functional significance of HSPB6: Gas activates adenylyl cyclase (AC) to stimulate production of cAMP. NO activates soluble guanylate cyclase (sGC) to stimulate production of cGMP. Intracellular accumulation of these nucleotides results in HSPB6 phosphorylation. Phosphorylated HSPB6 plays an important role in diverse physiological and pathological processes.

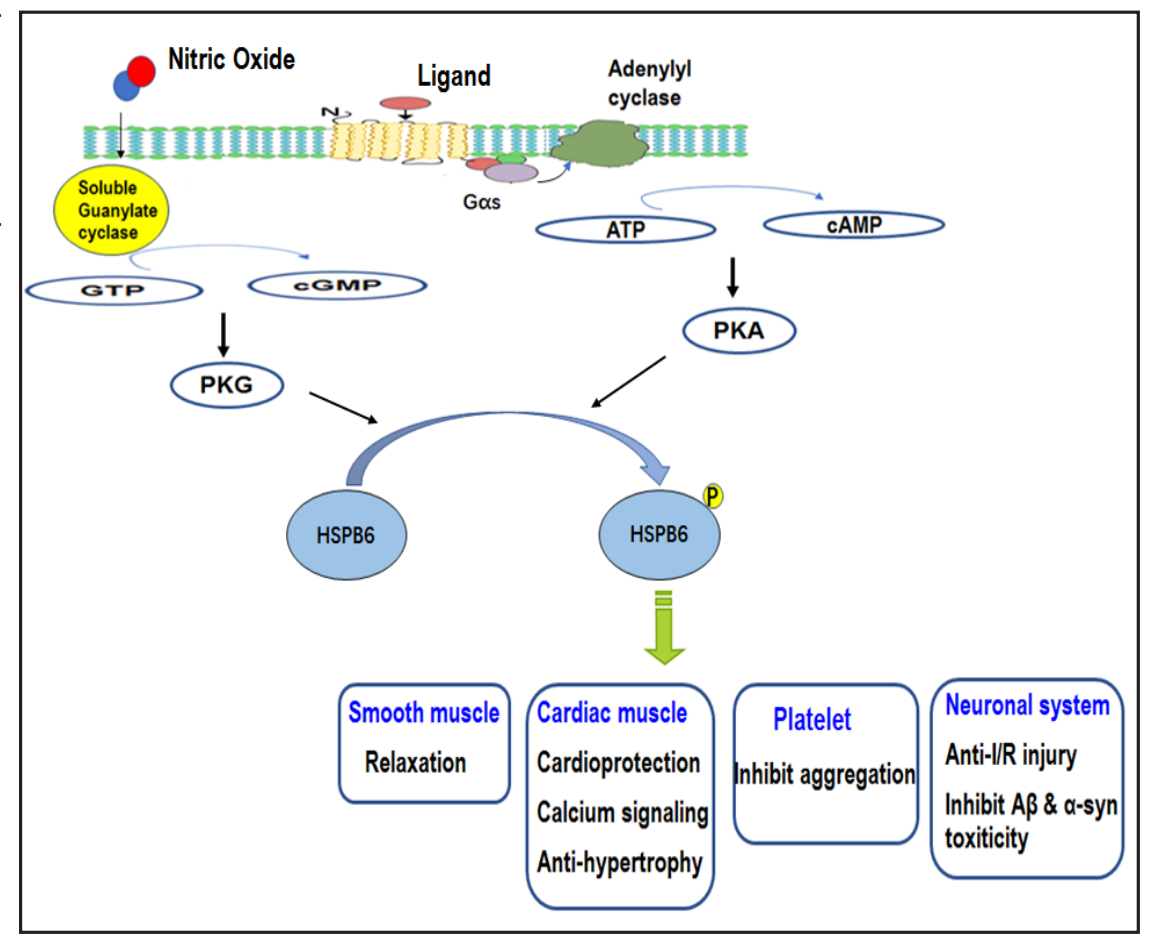

unfolded or misfolded protein by recruiting the co-chaperone Bag3. Formation of HSPB6Bag3 complex results from the interaction between the hydrophobic groove in the sHSP and two IPV (Ile-Pro-Val) motifs in Bag3[48]. Moreover, depletion of Bag3 also abrogated the chaperone activity HSPB6 towards the aggregation-prone protein HttQ43, indicating that HSPB6 is strictly dependent upon its binding to Bag3 to stimulate Htt43Q clearance [48]

Recently, peptides from HSPB6 and the HSPB1, with sequence homology to HSPB5, were demonstrated as molecular chaperones [49]. HSPB6 and HSPB1 peptides, despite performing better chaperone activities than the HSPB5 peptide, had the same degree of surface hydrophobicity as the HSPB5 peptide [49]. Such a disconnect between surface hydrophobicity and chaperone activity, thus, suggested that the hydrophobic surface of sHSP is not the sole determining factor for the chaperone activity.

\section{Posttranslational modification of HSPB6}

Accumulating evidence suggests that various post-translational modifications of HSPB6, including phosphorylation, acetylation and other modifications, provide an additional overlapping or parallel level of regulation at an epigenetic level thereby tailoring HSPB6 function to suit a specific cell type or environmental condition.

\section{Phosphorylation of HSPB6}

HSPB6 undergoes multisite phosphorylation. Insulin evokes phosphorylation at serine 157 of rat and swine HSPB6 through PI3K-dependent pathway [50]. In swine carotid artery, Ser157-HSPB6 phosphorylation was constitutively high and did not change during contractile activation or forskolin-induced relaxation [51]. Interestingly, Ser157 is not present in human HSPB6. Ser59 was detected after phosphorylation of purified rat skeletal muscle HSPB6 with PKA [7]. However, it is still unknown whether this site is phosphorylated in vivo. To date, most assumptions about the significance of HSPB6 phosphorylation have been made for serine 16, which is located within the sequence motif RRXS, a characteristic consensus motif for both PKA and PKG $[7,52]$. Actually, HSPB6 is the only sHSP that contains RRAS consensus sequence for cAMP-PKA phosphorylation [1]. The level of ser-16 phosphorylation increases 
after different kinds of stimulation, which triggers conformational changes of HSPB6, thereby it might expose additional interaction sites or increase interaction with other proteins. Through changes in protein-protein interactions, phosphorylation of HSPB6 thus may alter the protein functional activities. Mounting evidence suggests that HSPB6 phosphorylation promotes smooth muscle relaxation and initiates a variety of cardio-protective and neuroprotective effects (Fig. 1).

Despite the well-known extracellular stimuli that promote cAMP-responsive phosphorylation, less is understood about the subcellular signalling events regulating this modification. It is well known that a number of AKAPs play important pathophysiological roles in the heart, including AKAP-Lbc (also known as AKAP13) [23]. Recently, Edwards et al. indicated that AKAP-Lbc functions as the anchoring protein responsible for directing PKA phosphorylation of HSPB6 on Ser16 and suggested that an AKAP-Lbc-HSPB6-PDE4 complex resides in the cytoplasm of cardiac cells [53]. Under resting conditions, PDE4 bound to HSPB6 hydrolyses cAMP, which prevented activation of local PKA, thereby maintaining HSPB6 in a hypophosphorylated state. Upon stress, elevated levels of cAMP swamp this signal termination mechanism to activate AKAP-Lbc-bound PKA and subsequently phosphorylate HSPB6[53, 54]. Certain PDE4 Inhibitors induce phosphorylation of HSPB6 in a dose-and time-dependent manner, which may attenuate the $\beta$-agonist induced hypertrophic response in cardiac myocytes [54] and promote association of the chaperon with $A \beta$ to decrease $A \beta$ induced cytotoxicity [55].

\section{Acetylation of HSPB6}

An increase in acetylated HSPB6 in response to KDAC inhibition identified it as a novel target of acetylation. Acetylation of this chaperon functions as a mechanism for modulating vascular and nonvascular smooth muscle contractility. Surprisingly, upon KDAC inhibition, an increase in acetylated HSPB6 detected both in non-smooth muscle and smooth muscle, accompanied with increased ser16 phosphorylation [56]. The results suggested potential synergistic influence of two different posttranslational modifications on smooth muscle relaxation. The mechanism underlying the increased ser16 phosphorylation upon KDAC inhibition remains largely unknown. The possible explanation is that following KDAC inhibition, acetylation of PKA/PKG or proteins that interact with these kinases increase their activity toward HSPB6[56].

\section{MGO modification of HSPB6}

As HSPB5 and HSPB1, HSPB6 easily undergoes modification by MGO, the efficiency of which is dependent MGO concentration [57]. Certain sites accessible to MGO modification (Arg13, Arg14, Arg27) are located in the vicinity of Ser16, the main site of phosphorylation. Even mild MGO modification significantly inhibited phosphorylation of HSPB6 by cyclic AMPdependent protein kinase [58]. Susceptibility to trypsinolysis and chaperone-like activity of HSPB6 were also affected by both mild and extensive MGO modification.

\section{Interaction of HSPB6 with other SHSPs}

Formation of complexes between different sHSPs is well established. The multiple data of literature indicate that HSPB1, HSPB5 and HSPB6 are able to form heterooligomeric complexes and stressful conditions induce modification of the interactions between these sHSPs [59]. HSPB1 and HSPB6 preferentially form hetero-oligomers over interactions with other orthologues, which form at least two different complexes with apparent molecular masses 100-150 and 250-300 kDa dependent on temperature [60]. The formation of heterooligomeric complex affected the rate of HSPB6 phosphorylation and by this means might regulate different processes depending on phosphorylation of HSPB6. It is well accepted that both HSPB1 and HSPB6 are characterized by their incredible number of fundamental cellular roles. The pleotropic activities have been reported to result of their 
interaction with a number of protein clients and practically all sHSPs. The pleotropic functions of the sHSPs result from their interaction with many different client proteins. Inside of the heterooligomeric complexes, HSPB1 and HSPB6 mutually affect the structure of each other and therefore influence the accessibility of certain sites to different protein clients, HSPB6 forming heterooligomer with HSPB1 thus might lead to displacement of other protein partners and subsequently affect many functions that are dependent on these sHSPs interactomes.

As HSPB6 does not contain the canonical C-terminal IXI/V motif, HSPB6 CTD has been indicated little to no influence on the preferred association of HSPB1. The various sHSP truncations ultimately point to different sequences within the NTD of HSPB6 influencing the size and stability of the HSPB1-HSPB6 hetero-oligomers, which is consistent with the previous finding indicating the importance of NTD in typical HSPB6 oligomer assembly, as we reviewed in section 1 .

It is worthy to note that in the presence of TMAO, HSPB6 and HSPB1 form only one type of heterooligomeric complex with apparent molecular weight of $\sim 430 \mathrm{kDa}$ [61]. Therefore, TMAO may induce changes of HSPB6 quaternary structure and modulate its interaction with HSPB1. Recently published data indicated the interactions of HSPB6 with HSPB8[62]. In addition, HSPB2 form mixed complexes with HSPB6 at level of dimer [63]. Though the effect induced by the interaction between sHSPs is still obscure, several sHSPs that express in the same cell and form multiple combinatorial chimeric oligomeric complexes could bear new protein target recognition abilities, subsequently modulating those molecules [64].

\section{Role of HSPB6 in smooth muscle relaxation}

The role of HSPB6 as a mediator of smooth muscle relaxation has been widely recognized and potential mechanism of action of phosphorylated HSPB6 in smooth muscle has been elucidated. Both Cyclic nucleotide-dependent and endothelium-dependent vasorelaxation are associated with increased phosphorylation of HSPB6. In models in which vascular relaxation is impaired, HSPB6 is not phosphorylated. Increases in the phosphorylation of HSPB6 neither occur in umbilical artery smooth muscle, which is uniquely refractory to cyclic nucleotide-dependent vasorelaxation, nor in rabbit bladder smooth muscle, which is also refractory to cyclic nucleotide-dependent relaxation. There were impaired endothelium-independent and endothelium-dependent relaxation in cerebral vessels after $\mathrm{SAH}$, which was demonstrated to be associated with decreased expression of both total and phosphorylated HSPB6. On the other hand, extent of HSPB6 phosphorylation quantitatively correlated with cyclic nucleotide-dependent vascular, uterine, airway and bladder smooth muscle. In isolated perfused bovine carotid arteries, endothelial-dependent vasodilation was also demonstrated to be mediated by increased HSPB6 phosphorylation.

Additionally, transfection of wildtype HSPB6 promoted relaxation. Transduction of peptide analogs of phospho-HSPB6 containing the phosphorylation site on HSPB6 and phosphatase-resistant mimics of the phosphorylation site(S16E) also inhibited contraction, whereas Ser16 to Ala HSPB6 mutants did not. Collectively, these data suggested that the HSPB6 phosphorylation played a significant role in smooth muscle relaxation. However, the detailed mechanism of this process is still not well-understood. Brophy etal. demonstrated the association of HSPB6 with actin, in particular, the association of phosphorylated HSPB6 with nonfilamentous actin [65]. According to their data, during contraction, unphosphorylated HSPB6 is bound to actin filaments and $\alpha$-actinin, whereby stabilizes actin filaments and their fixation to dense bodies interacting with the cell membrane; after phosphorylation, HSPB6 dissociates from polymerized actin and $\alpha$-actinin. This prevents transduction of force generation and results in relaxation. In contrast to this viewpoint, Rembold et al. suggested that phosphorylated HSPB6 increases affinity of HSPB6 to actin filaments. They demonstrated a putative actin-tropomyosin binding region of HSPB6 (the amino acid residues 110-121, which is highly analogous to cardiac troponin I residues 136-147) [52]. It 


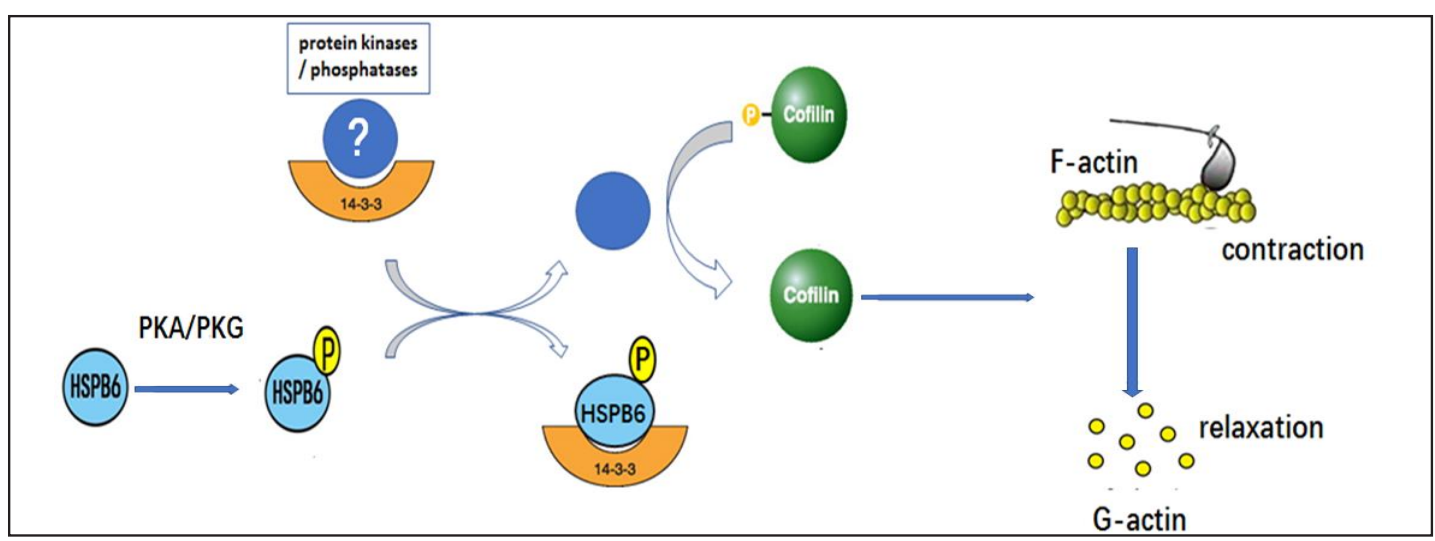

Fig. 2. Schematic diagram of HSPB6 in smooth muscle relaxation. Phosphorylated HSPB6 induces displacement of certain protein kinases (or protein phosphatases) from their complexes with 14-3-3, which dephosphorylates and activates cofilin. Activated cofilin severs actin filaments and induced actin depolymerization.

is postulated that phosphorylated HSPB6 is tightly bound to actin and is switching off actin filaments just as troponin I, preventing attachment of phosphorylated cross-bridges to the filaments [52]. Though the mechanism of HSPB6 action proposed by the two groups was completely different, their data unequivocally favor that HSPB6 may be modulating smooth muscle relaxation by a direct association with cytoskeletal or contractile elements (actin or certain actin-binding proteins).

However, it is very surprising that stoichiometry of the complex formed by HSPB6 and actin is indeed very low and is independent of the phosphorylation of HSPB6[66]. In addition, as mentioned above, HSPB6 is predominantly localized to the cytoplasm where it forms tight complexes with HSPB5 and HSPB1. All these facts make the direct involvement of HSPB6 in regulation of actin filaments very questionable. If HSPB6 is not a genuine actin-binding protein, then the question arises: how can HSPB6 participate in the regulation of smooth muscle contraction? One hypothesis is that HSPB6 somehow affects actin polymerization. The phosphorylated HSPB6 has been indicated to interact and form tight complexes with 14-3-3 protein. Upon phosphorylation, HSPB6 may displace phosphorylated cofilin from its complex with 14-3-3, followed by rapid dephosphorylation of cofilin, which induces actin depolymerization and smooth muscle relaxation $[67,68]$. If it is true, the other question is that cofilin only weakly interacts with 14-3-3 [69]. How can it directly compete with phosphorylated HSPB6 for its binding to 14-3-3? It is now accepted that phosphorylated HSPB6 might induce displacement of certain binding partners of 14-3-3 which involved in (de)phosphorylation of cofilin, subsequently regulating cofilin-dependent reorganization of cytoskeleton [69] (Fig. 2). Though the exact mechanisms remain enigmatic, the significance of phosphorylated HSPB6 in smooth muscle relaxation has been elucidated. Therefore, drugs that mimic phosphorylated HSPB6 are promising candidates as vasodilators and bronchodilators.

\section{Role of HSPB6 in Cardioprotection}

Mounting evidence supports the protective role of HSPB6 against a number of pathophysiological cardiac processes. Importantly, S16D mutants (phosphomimics of HSPB6) provided even greater protection against apoptosis than the wild type HSPB6, whereas the S16A (phospho-null mutants) mutant conferred no such protection [42, 70]. Naturally occurring mutants of HSPB6 at position 20 (P20L substitution), associated with diminished Ser16 phosphorylation, abrogated the anti-apoptotic effects of HSPB6 completely [71]. Therefore, phosphorylation of HSPB6 at Ser16 is vital for its cardioprotective actions. 


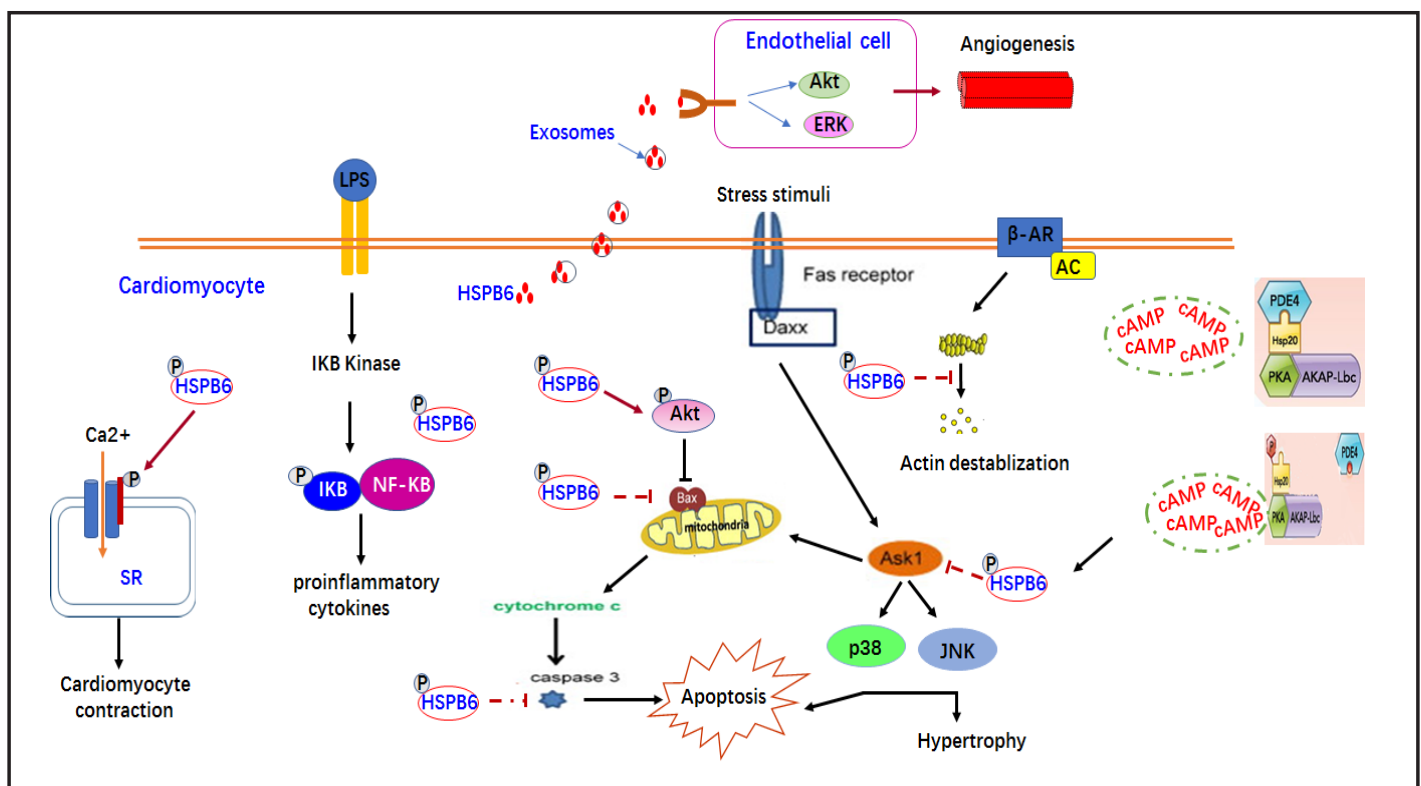

Fig. 3. Proposed schematic diagram of multi-level protective effects of HSPB6 in the heart. Cardiac HSPB6 and its phosphorylation are inducible by various stimuli. The phosphorylated active HSPB6 consequently interacts with apoptosis-related proteins such as Bax, p-Akt, which lead to restriction of cytochrome $\mathrm{C}$ release and repression of caspase- 3 activation. Its interaction with actin and may stabilize the microfilaments, also leading to protection against cardiac apoptosis. Disruption of the PDE4-HSPB6 complex which results in highly phosphorylated HSPB6 attenuates ASK1-JNK/p38 signaling pathway, and contributes to its anti-hypertrophic effect. Phosphorylated HSPB6 also induces PLN phosphorylation which increases SR Ca2+ transport and thus enhances cardiac contractility. Moreover, HSPB6 is actively released from cardiomyocytes via exosomes. extracellular HSPB6 physically binds to the VEGF receptor and induces the angiogenic pathway.

A virtual explosion of interest has developed with regard to the mechanisms whereby phospho-HSPB6 confers cardioprotection and evidence from various research studies indicates that HSPB6 cardioprotective effects result from a synergism between multiple, intricate mechanisms. Key advances have been made in elucidating the significance of HSPB6 on cardiomyocyte contractile function, anti-apoptotic, anti-I/R injury and anti-hypertrophic effects (Fig. 3).

\section{Enhancing cardiomyocyte contractile function}

Pipkin et al. found that phosphorylated HSPB6 increased myocyte shortening rate through increases in calcium uptake and more rapid lengthening [32], consistent with the result reported by Chu et al [8]. Using loss-of-function and gain-of function approaches in adult rat cardiomyocytes, Wang et al. verified the correlation between HSPB6 expression and cardiac contractile function [25]. The underlying mechanisms appear to involve direct binding of phosphorylated HSPB6 to PP1 and inhibition of PP1 activity, which allows for increases in the phosphorylation of PLN. PLN-phosphorylation increases SR Ca2+ transport rate and SERCA2a activity. Such an increase in Ca2+ transport is expected to contribute primarily to enhanced rates of cardiac contractility and relaxation [72, 73] (Fig. 4) .

Anti-apoptotic and I/R injury effects

HSPB6 improved cardiac function and prolonged cardiac survival after chronic administration of Doxorubicin, at least partly through interacting with p-Akt and preserving Akt phosphorylation [74]. Elevated HSPB6 could protect against LPS-induced 


\section{Cellular Physiology \begin{tabular}{l|l|l}
\hline and Biochemistry 10.1159/000484889 & $\begin{array}{l}\text { C } 2017 \text { The Author(s). Published by S. Karger AG, Basel } \\
\text { www.karger.com/cpb }\end{array}$
\end{tabular}

Fig. 4. A regulatory effect of phosphorylated HSPB6 on myocardial contracitility. Under basal conditions, PP1 interacts with and dephosphorylates PLN. Dephosphorylated PLN interacts with SERCA2a and inhibits the pumping activity. Following activation of the PKA, HSPB6 phosphorylation causes the dissociation of the PP1 from PLN and enables PP1 to bind with high affinity to phosphorylated HSPB6. This results in inhibition of PP1 and enhanced phosphorylation of PLN. Phosphorylation of PPN relieves its inhibition of the SERCA, which greatly stimulates the rate and amount of cytosolic $\mathrm{Ca} 2+$ resequestered into the SR, enhancing myocardial contracitility.

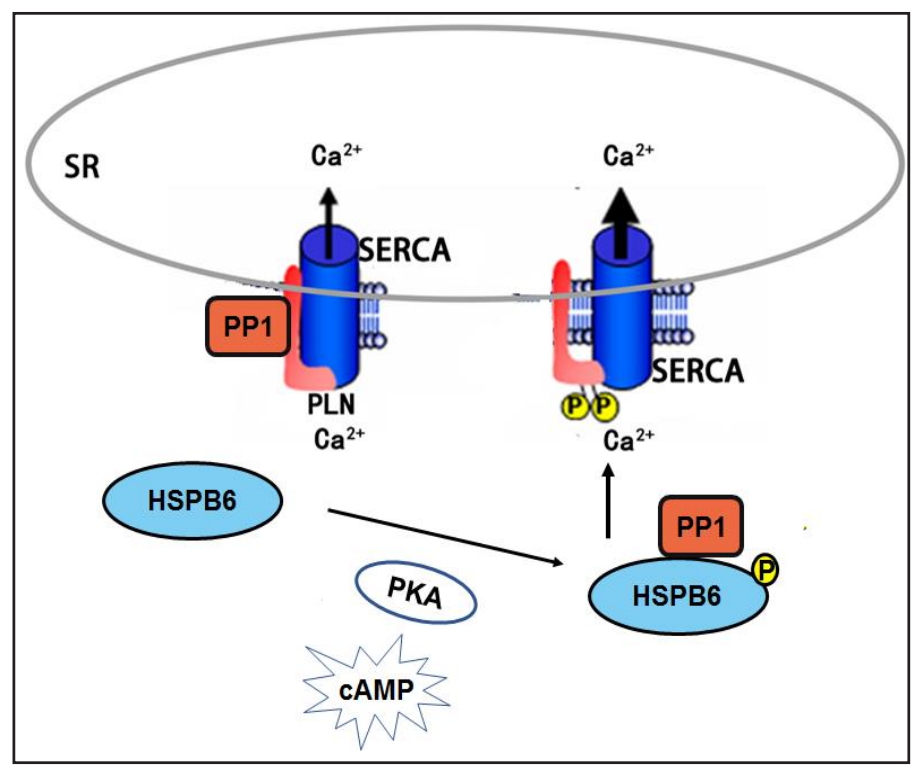

cardiac dysfunction, may via interacting with NF-B and inhibiting its activation, which is responsible for proinflammatory cytokine syntheses [25]. Phosphor-HSPB6 also provides cardioprotection against $\beta$-agonist-induced apoptosis, possibly caused by its reduced actinstabilization activity and inhibition of the conversion of procaspase-3 to active caspase-3[42]. One of the commonest causes of heart failure is myocardial ischemia. Accumulating evidence has implicated HSPB6 as a key mediator of cardioprotection against I/R injury. Zhu et al. reported that HSPB6-overexpressing H9c2 cells were resistant to simulated I/R condition and that gene transfer of HSPB6 in rat hearts successfully conferred protection against I/R-induced injury [75]. Consistently, a subsequent study by Fan indicated that HSPB6 overexpression in the heart was associated with better recovery of cardiac function and reduced infarction in the following I/R injury [76]. Conversely, transgenic mice with cardiac-specific overexpression of miR-320 revealed an increased extent of apoptosis and infarction size in the hearts on I/R relative to the wild-type controls via antithetical regulation of HSPB6[26]. Mechanistic studies unveiled that HSPB6 directly interacted with Bax and the cardioprotective effect may be mediated through preventing Bax translocation to the mitochondria, which blocked the initiation of apoptosis [76]. Furthermore, HSPB6 served as a novel cardiokine in regulating myocardial angiogenesis through activation of the VEGFR signaling cascade [45]. Collectively, overexpression of HSPB6 in the heart not only resists stress-triggered cardiomyocyte death via the intrinsic anti-apoptotic pathways, but also increases capillary density by VEGF, which may further enhance the survival of cardiomyocytes.

\section{Anti-hypertrophic action}

Cardiac overexpression of HSPB6 has also been found to protect heart against $\beta$-agonistinduced remodeling. The benefit may be attributed to the attenuation of the ASK1-JNK/ p38 signaling pathway [42]. Disruption of the PDE4-HSPB6 complex which led to highly phosphorylated endogenous HSPB6 attenuated $\beta$-agonist-induced hypertrophy, highlighting the importance of phosphorylation status of HSPB6 on its cardioprotective effects [54]. More recently, PKD1 was identified as a novel partner for HSPB6 and was suggested to bind directly to the HSPB6 to enable HSPB6 phosphorylation at a PKD1 consensus site, which contains serine $16[77,78]$. In the study of Sin et al., cardioprotection was reported to be induced by disruption of PKD1-HSPB6 complex, which should result in a reduction of HSPB6 phosphorylation [78]. The result contradicted the previous notion that increased PKA phosphorylation of HSPB6 functions as a cardioprotective mechanism [79]. Thus, 
different kinases can elicit opposite effects even though the phosphorylation takes place on the same Ser/Thr residue. As effect of PKA inhibition and PKD1-HSPB6 complex disruption on HSPB6 phosphorylation was indicated additive, the hypothesis is that the functional roles of HSPB6 associated with its phosphor-Ser16 status result from two opposing kinase activation within 'sub - pools' of HSPB6. The balance between PKA and PKD1 activation is thus likely to cue the consequence of a hypertrophic response

Cardiac-specific overexpression of HSPB6 also remarkably attenuated diabetes-induced cardiac dysfunction and adverse remodeling [80]. Interestingly, elevation of HSPB6 levels not only increased secretion of protective exosomes but also reprogrammed detrimental exosomes generated in cardiomyocytes [80]. As exosome has been well studied as a critical tool for cell-to-cell communication [81], the HSP-mediated intrinsic protective message could be spread out via exosomes to whole tissue/organ, even whole body. Thus, HSPB6engineered exosomes might be a novel therapeutic agent for diabetic cardiomyopathy.

\section{Potential Regulator of Platelet Functions}

HSPB6 inhibits the aggregation of platelets induced by thrombin or botrocetin but not ADP. Thrombin evokes cytoplasmic free calcium elevation in platelets by both the release from intracellular calcium stores in early phase and the influx of extracellular calcium in the late phase [82]. HSPB6 was found to block thrombin-induced calcium influx, having little inhibition to calcium release from intracellular calcium stores [43]. Additionally, endothelial injury induced release of HSPB6 from artery wall to plasma, which participate in inhibition of platelet aggregation extracellularly [44]. Plasma HSPB6 binds to platelets through specific binding sites and inhibited thrombin-induced phosphoinositide hydrolysis by phospholipase $\mathrm{C}$ in human platelets, indicating that extracellular HSPB6 inhibited platelet aggregation through the suppression of the intracellular transducing event [44]. Short peptides of HSPB5 (9WIRRPFFPF17) and of HSPB6 (11WLRRASAPL19) effectively prevent platelet aggregation induced by thrombin, botrocetin, ristocetin, but not by collagen and ADP via dual prevention of PAR-1 and GPIb/V/IX-VWF axis [83], which are essential for platelet activation and thrombus formation. Thus, short peptides of HSPB5 and HSPB6 are considered as potential new pharmaceutical compounds in antithrombotic therapy and ischemic diseases.

\section{Role of HSPB6 in Cancer}

Accumulating evidence supports HSPB6 as an inhibitor of neoplastic growth. For example, the expression of HSPB6 in human HCC cells inversely correlated with the TNM stage. HSPB6 reportedly inhibited the proliferation of HCC cells via suppression of the MAPK family, including JNK and the PI3K/Akt pathway [84, 85]. Furthermore, in consistent with the previous result that HSPB6 inhibited LPS-induced NF- $\kappa$ B activation in cardiomyocytes, HSPB6 acts as a negative regulator of HCC via down-regulation of TNF- $\alpha$-stimulated IKK/IкB/NF$\kappa \mathrm{B}$ pathway [86]. Additionally, HSPB6 directly associated with Bax, whereby it stimulated caspase cascade and induced apoptosis in HCC [11]. Collectively, HSPB6 might suppress HCC cell growth via both the downregulation of cell proliferation signals and the activation of apoptosis pathway. Reduced HSPB6 expression was related to poor prognosis and was revealed as a pro-death protein in colorectal cancer cells [87]. In normal mouse heart, overexpressed HSPB6 reportedly interacts with the Bax protein, which may prevent its translocation to the mitochondria and block the initiation of apoptosis after I/R injury [76]. Moreover, HSPB6 and its phosphorylation at Ser16 provided cardioprotection against $\beta$-agonist-induced apoptosis in rat cardiomyocytes [42]. Collectively, HSPB6 can be either anti-apoptosis or pro-apoptosis depending on the cell types and conditions. Since HSPB6 is likely to act at the level of several different signaling pathways, it may contribute in a very significant way to the eventual outcome associated with different death stimuli.

\section{KARGER}


Changes in HSPB6 expression have been found in several other cancers. In gliomas, HSPB6 was reproducibly downregulated in tissue specimens when compared to normal brain tissues [88]; in primary lung cell adenocarcinomas HSPB6 was substantially downregulated [89]. Mean anti-HSPB6 antibody concentrations were negatively correlated with ovarian cancer malignancy. In addition, HSPB6 expression declined in high-grade squamous intraepithelial lesions and cervical carcinoma cells [90]. As an example of a uniformly low expression pattern in cancers, HSPB6 appears to have a prognostic value in a broad range of cancers.

Recent advances in the field of epigenetics have pointed to epigenetic alterations as critical changes involved in human cancer cells in addition to numerous genetic alterations. Methylation of cytosine residues at CpG dinucleotides is a well-described epigenetic DNA modification, and aberrant $\mathrm{CpG}$ methylation patterns are known to contribute to tumorigenesis [91]. The promoter region of the HSPB6 gene was found to be hypermethylated, which inversely correlated with HSPB6 transcript levels, in melanoma cells when compared with normal melanocytes [12]. Furthermore, HSPB6 promoter hypermethylation significantly increased during melanoma development, implying that HSPB6 as a specific marker could be associated with melanoma progression and be used to predict melanoma prognosis.

\section{Role of HSPB6 in Neuronal Diseases}

\section{Neurodegenerative Disease}

$\mathrm{AD}$ is a neurodegenerative disorder characterized pathologically by SP, NFTs and CAA [92]. $A \beta$ is a major protein component of SP and CAA in AD. Increases in A $\beta$ levels, followed by an imbalance between the rates of production and clearance of the peptide, promote $A \beta$ oligomerisation and lead to the formation of insoluble fibrillar deposits and soluble $A \beta$ oligomers [93], both of which promote neuronal dysfunction and cell death leading to neurodegeneration. SP and CAA are also neuropathological hallmarks of HCHWA-D [94]. Studies performed over decades have come to a consensus that generation of toxic $A \beta$ is an important driver of neurodegeneration. Prevention of aggregation of $A \beta$ into its toxic oligomeric or fibril forms, thus, is the focus of therapeutic strategies for neurodegenerative diseases.

HSPB6 was demonstrated to be colocalized with the pathological hallmarks of AD brains. In AD brain, HSPB6 predominantly associates with nonfibrillar $A \beta$ in diffuse SPs, whereas in HCHWA-D brain, colocalization of HSPB 6 with A $\beta$ in both CAA and SPs has been observed [13, 95]. The co-localization of HSPB6 with A $\beta$ aggregates suggests that HSPB6 may play a role in the deposition of A $\beta$. Expression of HSPB6 has also been observed in reactive astrocytes and microglia surrounding both SP and CAA, possibly as part of the stress response in these reactive cells [13]. Indeed, while most other sHSPs inhibit $A \beta(1-40)$ aggregation at molar ratios of chaperone to $A \beta(1-40)$ of $1: 10$ to $1: 100$, HSPB6 surprisingly reduces $A \beta(1-40)$ fibril formation and attenuates its toxicity at molar ratios near 1:1000 or lower [46], making HSPB6 unique among all the A $\beta$ aggregation inhibitors reported in the literature. Later, using a different target cell type, Wilhelmus et al. demonstrated that the HSPB6 bound to both $A \beta 1-40$ and $A \beta 1-42$ and reduced or completely inhibited their aggregations. Furthermore, the sHSP was reportedly effective inhibitor of the cerebrovascular toxicity of $A \beta$ (both $A \beta 1-40$ and $A \beta 1-42$ ) in vitro [96]. Mechanism research mapped the sites of interaction on both HSPB6 and A $\beta$. PKA/PKG consensus site (RRAS) on HSPB6 directs association of the chaperone with $A \beta$ on a motif that is proximal to the $A \beta$ oligomerization domain, which has been found to be essential to cytotoxic aggregate formation [97]. PKA/PKG phosphorylation of the chaperone enhances its association with $A \beta$, which serves to reduce the formation of higher order $A \beta$ oligomers.

$A \beta$ also triggers neuroinflammation [98] and HSPB6 was found to induce a much more pronounced IL-6 secretion than $A \beta$ itself in various cerebral cell cultures [97]. Interestingly, 
the proinflammatory effect of HSP6 does not seem to be limited to a single parameter, it also modulates multiple inflammatory factors including ICAM-1, IL-8 and MCP-1[99].

According to these findings, HSPB6 not only affects $A \beta$ accumulation and aggregation, but also may contribute to the neuropathology by actively triggering the inflammatory reactions in both $\mathrm{AD}$ and HCHWA-D.

The $\alpha$-synucleinopathies are a group of neurodegenerative disorders, including PD, MSA, and DLB, in which aggregation of $\alpha$-syn into protein inclusions is a critical step in the molecular mechanism [100]. HSPB6 could interact WT and mutant $\alpha$-syn and inhibit its fibril formation. In his way, HSPB6 protect cells from the toxicity associated with $\alpha$-syn aggregation [14].

Thus, through intracellular handling of misfolded proteins, HSPB6 acts as a key component of the proteostasis network and maintains cell viability. Therefore, boosting its expression may be an interesting therapeutic target in the prevention and treatment of neurodegenerative diseases.

\section{Ischemic injury}

While HSPB6 is constitutively highly expressed in muscular tissues, it showed much lower expression in brain. Under conditions of stress, inducible HSPB6 is highly upregulated to maintain cellular homeostasis and to develop cell survival functions. HSPB6 expression was observed in apical dendrite in CA1 pyramidal cells before the DNA migration from the nuclei into the apical dendrite, which suggested a strong relationship between HSPB6 and CA1 neuronal cell apoptosis. In mouse N2A cells, we showed that increased HSPB6 protein level could protect against OGD/R-induced apoptosis [15], which may be achieved through interaction with Bax and subsequent amelioration of the OGD/R-induced Golgi fragmentation [101]. Phosphorylation is important in regulating HSPB6's neuroprotection in our study. Consistently, in a rat model of ischemic stroke, exercise preconditioning-mediated neuronal and glial overexpression of HSPB6 contributes to functional recovery and neuronal and glial survival [102]. Currently, inhibition of miR-320, which dramatically elevates the expression of phospho-HSPB6 in the spinal cord, has been demonstrated to attenuate neurologic injuries induced by transient spinal cord ischemia [103]. Collectively, HSPB6 is a potential endogenous protector that may represent a therapeutic target in ischemiareperfusion injury in both brain and spinal cord.

\section{Conclusion}

In summary, HSPB6 is ubiquitously expressed in a number of tissues. The expression and phosphorylation of HSPB6 are regulated by different stimuli suggesting that HSPB6 may play an important role upon different forms of stress. HSPB6 is inactive or partially active under physiological conditions and converts to an active phosphorylated state upon stress. HSPB6 phosphorylation is thought to be a key step for its protective activity. Phosphorylated HSPB6 is located in the nodes of complex protein networks and exerts its salutary effects by interacting with multiple different partners and regulating various signal pathways. Mounting evidence support the versatility of HSPB6 such as inducing smooth muscle relaxation, inhibiting platelet aggregation and functioning as a key mediator of cardioprotection and neuroprotection. Moreover, HSPB6 exhibits chaperon activity, playing an important "housekeeping" role and protects the cell under different unfavorable conditions. It has been indicated to associate with $A \beta$ and $\alpha$-syn, which then influences their formation of higher order oligomers and inhibits their toxiticity. Thus, optimization of the interaction between HSPB6 and amyloidogenic fragment may be an interesting target for therapeutic intervention in neurodegenerative diseases. Recent researches also indicate that the expression of HSPB6 was negatively correlated with malignancy in several cancer tissues, thus it might have a prognostic value and may be a promising therapeutic agent for cancer treatment. 


\section{Cellular Physiology Cell Physiol Biochem 2017;44:314-332

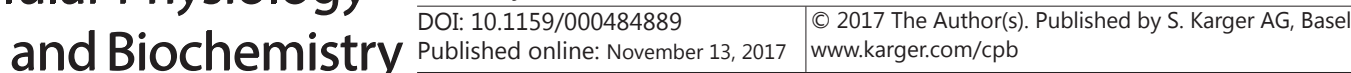 \\ Li et al.: Versatility of HSPB6}

\section{Abbreviations}

$\alpha$ - syn (alpaha synuclein); $\mathrm{A} \beta$ ( $\beta$-Amyloid); AD (Alzheimer's disease); AKAP (A-kinase anchoring protein); ASK (Apoptosis signal-regulating kinase); Bag3 (co-chaperone BCL2associated athanogene 3); Bax (Bcl-2-associated protein); Bcl-2 (B-cell lymphoma-2); CAA (cerebral amyloid angiopathy); CTE (C-terminal extension); CNS (central nervous system); DLB (dementia with Lewy bodies); GM (grey matter); HCC (human hepatocellular carcinoma); HCHWA-D (hereditary cerebral hemorrhage with amyloidosis of the Dutch type); ICAM-1 (Intercellular Adhesion Molecule 1); IKK (inhibitor of kappa B); IL (interleukin); I/R (ischemia/reperfusion); JNK (c-Jun N-terminal kinase); KDAC (lysine deacetylase); LPS (lipopolysaccharides); MAPK (mitogen-activated protein kinase); MCP-1 (Monocyte chemoattractant protein-1); MGO (methylglyoxal); MS (multiple sclerosis); MSA (multiple system atrophy); NF- $\kappa \mathrm{B}$ (nuclear factor kappa-light-chain-enhancer of activated B cells); NFT (neurofibrillary tangle); NTD (N- terminal domain); OGD/R (oxygen-glucose deprivation and reperfusion); PD (parkinson's disease); PDE (phosphodiesterase); PI3-k/ Akt phosphoinositide (3-kinase/protein kinase B); PKA (cAMP-dependent protein kinase); PKG (cGMP-dependent protein kinase); PKD (protein kinase D); PLN (phopholamban); PP1 (type 1 phosphatase); SAH (Subarachnoid hemorrhage); SERCA2a (SR Ca2+-ATPase); sHSP (small heat shock protein); SP (senile plaque); SR (sarcoplasmic reticulum); TMAO (trimethylamine N-oxide); TNM (TNM Classification of Malignant Tumours (tumour, node and metastasis)); VEGFR (vascular endothelial growth factor receptor); WM (white matter).

\section{Disclosure Statement}

The authors declare that there is no conflict of interest regarding the publication of this paper.

\section{References}

1 Kato K, Goto S, Inaguma Y, Hasegawa K, Morishita R, Asano T: Purification and characterization of a 20-kDa protein that is highly homologous to $\alpha$ B crystallin. J Biol Chem 1994;269:15302-15309.

-2 Beall AC, Kato K, Goldenring JR, Rasmussen H, Brophy CM: Cyclic nucleotide-dependent vasorelaxation is associated with the phosphorylation of a small heat shock-related protein. J Biol Chem 1997;272:1128311287.

-3 Bagnéris C, Bateman OA, Naylor CE, Cronin N, Boelens WC, Keep NH, Slingsby C: Crystal Structures of $\alpha$-Crystallin Domain Dimers of $\alpha$ B-Crystallin and Hsp20. J Mol Biol 2009;392:1242-1252.

-4 Heirbaut M, Beelen S, Strelkov SV, Weeks SD: Dissecting the functional role of the n-terminal domain of the human small heat shock protein HSPB6. PLoS One 2014;9:e105892.

-5 Weeks SD, Baranova EV, Heirbaut M, Beelen S, Shkumatov AV, Gusev NB, Strelkov SV: Molecular structure and dynamics of the dimeric human small heat shock protein HSPB6 J Struct Biol 2013;185:342-354.

-6 Bukach OV, Seit-Nebi AS, Marston SB, GusevNB: Some properties of human small heat shock protein Hsp20 (HSPB6). Eur J Biochem 2004;271:291-302.

7 Beall A, Bagwell D, Woodrum D, Stoming TA, Kato K, Suzuki A, Rasmussen H, Brophy CM: The small heat shock-related protein, HSP20, is phosphorylated on serine 16 during cyclic nucleotide-dependent relaxation. J Biol Chem 1999;274:11344-11351.

8 Chu G, Egnaczyk GF, Zhao W, Jo SH, Fan GC, Maggio JE, Xiao RP, Kranias EG: Phosphoproteome analysis of cardiomyocytes subjected to beta-adrenergic stimulation: identification and characterization of a cardiac heat shock protein p20 Circ Res 2004;94:184-193.

-9 Dreiza CM, Komalavilas P, Furnish EJ, Flynn CR, Sheller MR, Smoke CC, Lopes LB, Brophy CM: The small heat shock protein, HSPB6, in muscle function and disease. Cell Stress Chaperones 2010;15:1-11.

10 Fan GC, Chu G, Kranias EG: Hsp20 and its cardioprotection. Trends Cardiovasc Med 2005;15:138-141. 


\section{Cellular Physiology Cell Physiol Biochem 2017;44:314-332 \begin{tabular}{l|l} 
DOI: 10.1159/000484889 & $\begin{array}{l}\text { O 2017 The Author(s). Published by S. Karger AG, Basel } \\
\text { www.karger.com/cpb }\end{array}$
\end{tabular} \\ Li et al.: Versatility of HSPB6}

11 Nagasawa T, Matsushima-Nishiwaki R, Toyoda H, Matsuura J, Kumada T, Kozawa O: Heat shock protein 20 (HSPB6) regulates apoptosis in human hepatocellular carcinoma cells: Direct association with Bax. Oncol Rep 2014;32:1291-1295.

12 Koga Y, Pelizzola M, Cheng E, Krauthammer M, Sznol M, Ariyan S, Narayan D, Molinaro AM, Halaban R, Weissman SM: Genome-wide screen of promoter methylation identifies novel markers in melanoma. Genome Res 2009;19:1462-1470.

13 Wilhelmus MM, Otte-Höller I, Wesseling P, De Waal RM, Boelens WC, Verbeek MM: Specific association of small heat shock proteins with the pathological hallmarks of Alzheimer's disease brains. Neuropathol Appl Neurobiol 2006;32:119-130.

-14 Bruinsma IB, Bruggink KA, Kinast K, Versleijen AM, Segers-Nolten IM, Subramaniam V, Kuiperij HB, Boelens W, de Waal RM, Verbeek MM: Inhibition of $\alpha$-synuclein aggregation by small heat shock proteins. Proteins Struct Funct Bioinforma 2011;79:2956-2967.

15 Zeng L, Tan J, Hu Z, Lu W, Yang B: Hsp20 protects neuroblastoma cells from ischemia/reperfusion injury by inhibition of apoptosis via a mechanism that involves the mitochondrial pathways. Curr Neurovasc Res 2010;7:281-287.

16 van de Klundert FA, Smulders RH, Gijsen ML, Lindner RA, Jaenicke R, Carver JA, de Jong WW: The mammalian small heat-shock protein Hsp20 forms dimers and is a poor chaperone. Eur J Biochem 1998;258:1014-1021.

17 Shi J, Koteiche HA, McDonald ET, Fox TLStewart PL, McHaourab HS: Cryoelectron microscopy analysis of small heat shock protein 16.5 (Hsp16.5) complexes with T4 lysozyme reveals the structural basis of multimode binding. J Biol Chem 2013;288:4819-30.

18 Sluchanko NN, Chebotareva NA, Gusev NB: Quaternary structure of human small heat shock protein HSPB6 (Hsp20) in crowded media modeled by trimethylamine N-oxide (TMAO): Effect of protein phosphorylation. Biochimie 2015;108:68-75.

19 Peschek J, Braun N, Rohrberg J, Back KC, Kriehuber T, Kastenmüller A, Weinkauf S, Buchner J: Regulated structural transitions unleash the chaperone activity of B-crystallin. Proc Natl Acad Sci 2013;110:E3780-E3789.

20 Lambert H, Charette SJ, Bernier AF, Guimond A, Landry J: HSP27 multimerization mediated by phosphorylation-sensitive intermolecular interactions at the amino terminus. J Biol Chem 1999;274:93789385.

21 Inaguma Y, Hasegawa K, Kato K, Nishida Y: cDNA cloning of a 20-kDa protein (p20) highly homologous to small heat shock proteins: Developmental and physiological changes in rat hindlimb muscles. Gene 1996;178:145-150.

-22 Verschuure P, Tatard C, Boelens WC, Grongnet J-F, David JC: Expression of small heat shock proteins HspB2, HspB8, Hsp20 and cvHsp in different tissues of the perinatal developing pig. Eur J Cell Biol 2003;82:523530 .

23 Cross BE, O’Dea HM, MacPhee DJ: Expression of small heat shock-related protein 20 (HSP20) in rat myometrium is markedly decreased during late pregnancy and labour. Reproduction 2007;133:807-817.

-24 Rembold CM, Kaufman E: Heat induced HSP20 phosphorylation without increased cyclic nucleotide levels in swine carotid media. BMC Physiol 2003;3:3.

-25 Wang X, Zingarelli B, OConnor M, Zhang P, Adeyemo A, Kranias EG, Wang Y, Fan GC: Overexpression of Hsp20 prevents endotoxin-induced myocardial dysfunction and apoptosis via inhibition of NF-kappaB activation. J Mol Cell Cardiol 2009;47:382-390.

-26 Boluyt MO, Brevick JL, Rogers DS, Randall MJ, Scalia AF, Li ZB: Changes in the rat heart proteome induced by exercise training: Increased abundance of heat shock protein hsp20. Proteomics 2006;6:3154-3169.

-27 Fan G, Zhou X, Wang X, Song G, Qian J: Hsp20 interacting with phosphorylated Akt reduces Doxorubicintriggered oxidative stress and cardiotoxicity. Circ Res 2009;103:1270-1279.

28 Dohke T, Wada A, Isono T, Fujii M, Yamamoto T, Tsutamoto T, Horie M: Proteomic analysis reveals significant alternations of cardiac small heat shock protein expression in congestive heart failure. J Card Fail 2006;12:77-84.

-29 Kirbach BB, Golenhofen N: Differential expression and induction of small heat shock proteins in rat brain and cultured hippocampal neurons. J Neurosci Res 2011;89:162-175. 


\section{Cellular Physiology Cell Physiol Biochem 2017;44:314-332

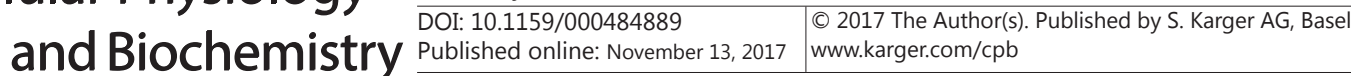

Li et al.: Versatility of HSPB6

-30 Wang X, Huang W, Liu G, Cai W, Millard RW, Wang Y, Chang J, Peng T, Fan GC: Cardiomyocytes mediate antiangiogenesis in type 2 diabetic rats through the exosomal transfer of miR-320 into endothelial cells. J Mol Cell Cardiol 2014;74:139-150.

-31 Macomson SD, Brophy CM, Miller W, Harris VA, Shaver EG: Heat shock protein expression in cerebral vessels after subarachnoid hemorrhage. Neurosurgery 2002;51:201-204.

-32 Pipkin W, Johnson JA, Creazzo TL, Burch J, Komalavilas P, Brophy C: Localization, macromolecular associations, and function of the small heat shock-related protein HSP20 in rat heart. Circulation 2003;107:469-476.

-33 Bartelt-Kirbach B, Golenhofen N: Reaction of small heat-shock proteins to different kinds of cellular stress in cultured rat hippocampal neurons. Cell Stress Chaperones 2014;19:145-53.

34 Yamasaki S, Anderson P: Reprogramming mRNA translation during stress. Curr Opin Cell Biol 2008;20:222-226.

-35 David JC, Boelens WC, Grongnet JF: Up-regulation of heat shock protein HSP20 in the hippocampus as an early response to hypoxia of the newborn. J Neurochem 2006;99:570-581.

-36 Niwa M, Hara A, Taguchi A, Aoki H, Kozawa O, Mori H: Spatiotemporal expression of Hsp20 and its phosphorylation in hippocampal CA1 pyramidal neurons after transient forebrain ischemia. Neurol Res 2009;31:721-727.

-37 Peferoen LA, Gerritsen WH, Breur M, Ummenthum KM, Peferoen-Baert RM, van der Valk P, van Noort JM, Amor S: Small heat shock proteins are induced during multiple sclerosis lesion development in white but not grey matter. Acta Neuropathol Commun 2015;3:87.

-38 Rembold CM, Zhang E: Localization of heat shock protein 20 in swine carotid artery. BMC Physiol 2001;1:10.

-39 Brophy CM, Dickinson M, Woodrum D: Phosphorylation of the small heat shock-related protein, HSP20, in vascular smooth muscles is associated with changes in the macromolecular associations of HSP20. J Biol Chem 1999;274:6324-6329.

40 Golenhofen N, Perng MD, Quinlan RA, Drenckhahn D: Comparison of the small heat shock proteins alphaB-crystallin, MKBP, HSP25, HSP20, and cvHSP in heart and skeletal muscle. Histochem Cell Biol 2004;122:415-425.

41 Verschuure P, Croes Y, van den IJssel PR, Quinlan RA, de Jong WW, Boelens WC: Translocation of small heat shock proteins to the actin cytoskeleton upon proteasomal inhibition. J Mol Cell Cardiol 2002;34:117-128.

42 Fan GC, Chu G, Mitton B, Song Q, Yuan Q Kranias EG: Small heat-shock protein Hsp20 phosphorylation inhibits $\beta$-agonist-induced cardiac apoptosis. Circ Res 2004;94:1474-1482.

43 Niwa M, Kozawa O, Matsuno H, Kato K, Uematsu T: Small molecular weight heat shock-related protein, HSP20, exhibits an anti-platelet activity by inhibiting receptor-mediated calcium influx. Life Sci 2000;66:712.

44 Kozawa O, Matsuno H, Niwa M, Hatakeyama D, Oiso Y, Kato K, Uematsu T: HSP20, low-molecular-weight heat shock-related protein, acts extracellularly as a regulator of platelet functions: A novel defense mechanism. Life Sci 2002;72:113-124.

45 Zhang X, Wang X, Zhu H, Kranias EG, Tang Y, Peng T, Chang J, Fan GC: Hsp20 functions as a novel cardiokine in promoting angiogenesis via activation of VEGFR2. PLoS One 2012;7:e32765

-46 Lee S, Carson K, Rice-Ficht A, Good T: Hsp20, a novel alpha-crystallin, prevents Abeta fibril formation and toxicity. Protein Sci 2005;14:593-601.

47 Kundu M, Sen PC, Das KP: Structure, stability, and chaperone function of alphaA-crystallin: role of N-terminal region. Biopolymers 2007;86:177-192.

48 Fuchs M, Poirier DJ, Seguin SJ, Lambert H, Carra S, Charette SJ, Landry J: Identification of the key structural motifs involved in HspB8/HSPB6-Bag3 interaction. Biochem J 2010;425:245-55.

49 Nahomi RB, Dimauro MA, Wang B, Nagaraj RH: Identification of peptides in human Hsp20 and Hsp27 that possess molecular chaperone and anti-apoptotic activities. Biochem J 2015;465:115-125.

50 Wang Y, Xu A, Pearson RB, Cooper GJ: Insulin and insulin antagonists evoke phosphorylation of P20 at serine 157 and serine 16 respectively in rat skeletal muscle. FEBS Lett 1999;462:25-30.

51 Meeks MK, Ripley ML, Jin Z, Rembold CM: Heat shock protein 20-mediated force suppression in forskolinrelaxed swine carotid artery. Am J Physiol Cell Physiol 2005;288:C633-C639. 


\section{Cellular Physiology Cell Physiol Biochem 2017;44:314-332 \begin{tabular}{l|l|l} 
DOI: 10.1159/000484889 & $\begin{array}{l}\text { O 2017 The Author(s). Published by S. Karger AG, Basel } \\
\text { www.karger.com/cpb }\end{array}$
\end{tabular}}

Li et al.: Versatility of HSPB6

52 Rembold CM, Foster DB, Strauss JD, Wingard CJ, Eyk JE: cGMP-mediated phosphorylation of heat shock protein 20 may cause smooth muscle relaxation without myosin light chain dephosphorylation in swine carotid artery. J Physiol 2000;524:865-878.

53 Edwards HV, Scott JD, Baillie GS: The A-kinase-anchoring protein AKAP-Lbc facilitates cardioprotective PKA phosphorylation of Hsp20 on Ser(16). Biochem J 2012;446:437-43.

-54 Sin YY, Edwards HV, Li X, Day JP, Christian F, Dunlop AJ, Adams DR, Zaccolo M, Houslay MD, Baillie GS: Disruption of the cyclic AMP phosphodiesterase-4 (PDE4)-HSP20 complex attenuates the $\beta$-agonist induced hypertrophic response in cardiac myocytes. J Mol Cell Cardiol 2011;50:872-883.

-55 Quinn SD, Dalgarno PA, Cameron RT, Hedley GJ, Hacker C, Lucocq JM, Baillie GS, Samuel ID, Penedo JC: Real-time probing of $\beta$-amyloid self-assembly and inhibition using fluorescence self-quenching between neighbouring dyes. Mol Biosyst 2014;10:34-44.

-56 Chen A, Karolczak-Bayatti M, Sweeney M, Treumann A, Morrissey K, Ulrich SM, Europe-Finner GN, Taggart MJ: Lysine deacetylase inhibition promotes relaxation of arterial tone and C-terminal acetylation of HSPB6 (Hsp20) in vascular smooth muscle cells. Physiol Rep 2013;1:e00127.

57 Muranova LK, Perfilov MM, Serebryakova MV, Gusev NB: Effect of methylglyoxal modification on the structure and properties of human small heat shock protein HSPB6 (Hsp20). Cell Stress Chaperones 2016;21:617-629.

58 Muranova LK, Perfilov MM, Serebryakova MV, Gusev NB: Effect of methylglyoxal modification on the structure and properties of human small heat shock protein HSPB6(Hsp20). Cell Stress Chaperones 2016;21:617-629.

-59 Sugiyama Y, Suzuki A, Kishikawa M, Akutsu R, Hirose T, Waye MM, Tsui SK, Yoshida S, Ohno S: Muscle develops a specific form of small heat shock protein complex composed of MKBP/HSPB2 and HSPB3 during myogenic differentiation. J Biol Chem 2000;275:1095-1104.

-60 Bukach OV, Glukhova AE, Seit-Nebi AS, Gusev NB: Heterooligomeric complexes formed by human small heat shock proteins HspB1(Hsp27) and HSPB6(Hsp20). Biochim Biophys Acta 2009;1794:486-495.

61 Sluchanko NN, Chebotareva NA, Gusev NB: Quaternary structure of human small heat shock protein HSPB6(Hsp20) in crowded media modeled by trimethylamine N-oxide(TMAO): Effect of protein phosphorylation. Biochimie 2015;108:68-75.

62 Fontaine JM, Sun X, Benndorf R, Welsh MJ: Interactions of HSP22 (HSPB8) with HSP20, alphaB-crystallin, and HSPB3 Biochem Biophys Res Commun 2005;337:1006-1011.

63 Boros S, Kamps B, Wunderink L, De Bruijn W, De Jong WW, Boelens WC: Transglutaminase catalyzes differential crosslinking of small heat shock proteins and amyloid-beta. FEBS Lett 2004;576:57-62.

64 Arrigo AP, Gibert B: Protein interactomes of three stress inducible small heat shock proteins: HspB1, HspB5 and HspB8. Int J Hyperthermia 2013;29:409-22.

65 Brophy CM, Lamb S, Graham A: The small heat shock-related protein-20 is an actin-associated protein. J Vasc Surg 1999;29:326-333.

66 Bukach OV, Marston SB, Gusev NB: Small heat shock protein with apparent molecular mass $20 \mathrm{kDa}(\mathrm{Hsp} 20$, HSPB6) is not a genuine actin-binding protein. J Muscle Res Cell Motil 2005;26:175-181.

67 Dreiza CM, Brophy CM, Komalavilas P, Furnish EJ, Joshi L, Pallero MA, Murphy-Ullrich JE, von Rechenberg M, Ho YS, Richardson B, Xu N, Zhen Y, Peltier JM, Panitch A: Transducible heat shock protein 20 (HSP20) phosphopeptide alters cytoskeletal dynamics. FASEB J 2005;19:261-263.

68 Chernik IS, Seit-Nebi AS, Marston SB, Gusev NB: Small heat shock protein Hsp20 (HSPB6) as a partner of 14-3-3gamma. Mol Cell Biochem 2007;295:9-17.

69 Sudnitsyna MV, Seit-Nebi AS, Gusev NB: Cofilin weakly interacts with 14-3-3 and therefore can only indirectly participate in regulation of cell motility by small heat shock protein HSPB6 (Hsp20). Arch Biochem Biophys 2012;521:62-70.

70 Qian J, Ren X, Wang X, Zhang P, Jones WK, Molkentin JD, Fan GC, Kranias EG: Blockade of Hsp20 phosphorylation exacerbates cardiac ischemia/reperfusion injury by suppressed autophagy and increased cell death. Circ Res 2009;105:1223-1231.

71 Nicolaou P, Knöll R, Haghighi K, Fan GC, Dorn GW 2nd, Hasenfub G, Kranias EG: Human mutation in the anti-apoptotic heat shock protein 20 abrogates its cardioprotective effects. J Biol Chem 2008;283:3346533471. 


\section{Cellular Physiology Cell Physiol Biochem 2017:44:314-332 \begin{tabular}{l|l|l} 
and Biochemistry $10.1159 / 000484889$ & $\begin{array}{l}\text { Do } 2017 \text { The Author(s). Published by S. Karger AG, Basel } \\
\text { www.karger.com/cpb }\end{array}$ \\
\hline
\end{tabular}}

Li et al.: Versatility of HSPB6

72 Qian J, Vafiadaki E, Florea SM, Singh VP, Song W, Lam CK, Wang Y, Yuan Q, Pritchard TJ, Cai W, Haghighi K, Rodriguez P, Wang HS, Sanoudou D, Fan GC, Kranias EG: Small heat shock protein 20 interacts with protein phosphatase-1 and enhances sarcoplasmic reticulum calcium cycling. Circ Res 2011;108:1429-1438. Vafiadaki E, Arvanitis DA, Sanoudou D, Kranias EG: Identification of a protein phosphatase-1/ phospholamban complex that is regulated by cAMP-dependent phosphorylation. PLoS One 2013;8:e80867 Fan GC, Zhou X, Wang X, Song G, Qian J, Nicolaou P, Chen G, Ren X, Kranias EG: Heat shock protein 20 interacting with phosphorylated akt reduces doxorubicin-triggered oxidative stress and cardiotoxicity. Circ Res 2008;103:1270-1279.

75 Zhu YH, Wang X: Overexpression of heat-shock protein 20 in rat heart myogenic cells confers protection against simulated ischemia/reperfusion injury. Acta Pharmacol Sin 2005;26:1076-1080.

76 Fan GC, Ren X, Qian J, Yuan Q, Nicolaou P, Wang Y, Jones WK, Chu G, Kranias EG: Novel cardioprotective role of a small heat-shock protein, Hsp20, against ischemia/reperfusion injury. Circulation 2005;111:17921799.

77 Sin YY, Baillie GS: Heat shock protein 20 (HSP20) is a novel substrate for protein kinase D1 (PKD1). Cell Biochem Funct 2015;33:421-426.

78 Sin YY, Martin TP, Wills L, Currie S, Baillie GS: Small heat shock protein 20 (Hsp20) facilitates nuclear import of protein kinase D 1 (PKD1) during cardiac hypertrophy. Cell Commun Signal 2015;13:16.

79 Edwards HV, Scott JD, Baillie GS: PKA phosphorylation of the small heat-shock protein Hsp20 enhances its cardioprotective effects. Biochem Soc Trans 2012;40:210-214.

-80 Wang X, Gu H, Huang W, Peng J, Li Y, Yang L, Qin D, Essandoh K, Wang Y, Peng T, Fan GC: Hsp20-mediated activation of exosome biogenesis in cardiomyocytes improves cardiac function and angiogenesis in diabetic mice. Diabetes 2016;65:3111-3128.

81 Ailawadi S, Wang X, Gu H, Fan GC: Pathologic function and therapeutic potential of exosomes in cardiovascular disease. Biochim Biophys Acta 2015;1852:1-11.

82 Feoktistov IA, Paul S, Hollister AS, Robertson D, Biaggioni I: Role of cyclic amp in adenosine inhibition of intracellular calcium rise in human platelets comparison of adenosine effects on thrombin- and epinephrine-induced platelet stimulation. Am J Hypertens 1992;5:147s-153s.

83 Kanno Y, Matsuno H: The possibility of novel antiplatelet peptides: the physiological effects of low molecular weight HSPs on platelets. Curr Pharm Des 2006;12:887-892.

84 Matsushima-Nishiwaki R, Adachi S, Yoshioka T, Yasuda E, Yamagishi Y, Matsuura J, Muko M, Iwamura R, Noda T, Toyoda H, Kaneoka Y, Okano Y, Kumada T, Kozawa O: Suppression by heat shock protein 20 of hepatocellular carcinoma cell proliferation via inhibition of the mitogen-activated protein kinases and AKT pathways. J Cell Biochem 2011;112:3430-3439.

-85 Matsushima-Nishiwaki R, Kumada T, Nagasawa T, Suzuki M, Yasuda E, Okuda S, Maeda A, Kaneoka Y, Toyoda H, Kozawa O: Direct association of heat shock protein 20 (HSPB6) with phosphoinositide 3-kinase (PI3K) in human hepatocellular carcinoma: Regulation of the PI3K activity. PLoS One 2013;8:6-13.

-86 Nagasawa T, Matsushima-Nishiwaki R, Yasuda E, Matsuura J, Toyoda H, Kaneoka Y, Kumada T, Kozawa O: Heat shock protein 20 (HSPB6) regulates TNF- $\alpha$-induced intracellular signaling pathway in human hepatocellular carcinoma cells. Arch Biochem Biophys 2015;565:1-8.

87 Ju YT, Kwag SJ, Park HJ, Jung EJ, Jeong CY, Jeong SH, Lee YJ, Choi SK, Kang KR, Hah YS, Hong SC: Decreased expression of heat shock protein 20 in colorectal cancer and its implication in Tumorigenesis. J Cell Biochem 2015;116:277-286.

88 Deighton RF, Short DM, McGregor RJ, Gow AJ, Whittle IR, McCulloch J: The utility of functional interaction and cluster analysis in CNS proteomics. J Neurosci Methods 2009;180:321-329.

89 Yap YL, Wong MP, Zhang XW, Hernandez D, Gras R, Smith DK, Minna JD, Danchin A, Wong MP: Conserved transcription factor binding sites of cancer markers derived from primary lung adenocarcinoma microarrays. Nucleic Acids Res 2005;33:409-421.

-90 Arnouk H, Merkley MA, Podolsky RH, Stoppler H, Santos C, Alvarez M, Mariategui J, Ferris D, Lee JR, Dynan WS: Characterization of molecular markers indicative of cervical cancer progression. Proteomics Clin Appl 2009;3:516-527.

-91 Sandoval J, Esteller M: Cancer epigenomics: Beyond genomics. Curr Opin Genet Dev 2012;22:50-55.

-92 Serrano-Pozo A, Frosch MP, Masliah E, Hyman BT: Neuropathological alterations in Alzheimer disease. Cold Spring Harb Perspect Med 2011;1:a006189 


\section{Cellular Physiology Cell Physiol Biochem 2017;44:314-332 \begin{tabular}{l|l|l} 
DOI: 10.1159/000484889 & $\begin{array}{l}\text { O } 2017 \text { The Author(s). Published by S. Karger AG, Basel } \\
\text { www.karger.com/cpb }\end{array}$
\end{tabular} \\ Li et al.: Versatility of HSPB6}

93 Harrison RS, Sharpe PC, Fairlie DP: Amyloid peptides and proteins in review. Rev Physiol Biochem Pharmacol 2007;159:1-77.

-94 van Duinen SG, Castaño EM, Prelli F, Bots GT, Luyendijk W, Frangione B: Hereditary cerebral hemorrhage with amyloidosis in patients of Dutch origin is related to Alzheimer disease. Proc Natl Acad Sci U S A 1987;84:5991-5994.

$\$ 95$ Wilhelmus MM, Boelens WC, Kox M, Maat-Schieman ML, Veerhuis R, de Waal RM, Verbeek MM: Small heat shock proteins associated with cerebral amyloid angiopathy of hereditary cerebral hemorrhage with amyloidosis (Dutch type) induce interleukin-6 secretion. Neurobiol Aging 2009;30:229-240.

-96 Wilhelmus MM, Boelens WC, Otte-Höller I, Kamps B, de Waal RM, Verbeek MM: Small heat shock proteins inhibit amyloid-beta protein aggregation and cerebrovascular amyloid-beta protein toxicity. Brain Res 2006;1089:67-78.

97 Cameron RT, Quinn SD, Cairns LS, MacLeod R, Samuel ID, Smith BO, Carlos Penedo J, Baillie GS: The phosphorylation of Hsp20 enhances its association with amyloid- $\beta$ to increase protection against neuronal cell death. Mol Cell Neurosci 2014;61:46-55.

-98 Moore AH, O'Banion M.: Neuroinflammation and anti-inflammatory therapy for Alzheimer's disease. Adv Drug Deliv Rev 2002;54:1627-1656.

99 Bruinsma IB, de Jager M, Carrano A, Versleijen AM, Veerhuis R, Boelens W, Rozemuller AJ, de Waal RM, Verbeek MM: Small heat shock proteins induce a cerebral inflammatory reaction. J Neurosci 2011;31:11992-12000.

100 Jellinger KA: Neuropathological spectrum of synucleinopathies. Mov Disord 2003;18:S2-12.

101 Zhong B, Hu Z, Tan J, Lu T, Lei Q, Chen C, Zeng L: Hsp20 Protects against oxygen-glucose deprivation/ reperfusion-induced golgi fragmentation and apoptosis through Fas / FasL pathway 2015;2015:606934.

102 Lin CM, Chang CK, Chang CP, Hsu YC, Lin MT, Lin JW: Protecting against ischaemic stroke in rats by heat shock protein 20-mediated exercise. Eur J Clin Invest 2015;45:1297-1305.

103 He F, Shi E, Yan L, Li J, Jiang X: Inhibition of micro-ribonucleic acid-320 attenuates neurologic injuries after spinal cord ischemia. J Thorac Cardiovasc Surg 2015;150:398-406. 